Original

\title{
Effect of a Large Dose of Di (2-ethylhexyl) phthalate (DEHP) on Hepatic Peroxisome in Cynomolgus Monkeys (Macaca Fascicularis)
}

\author{
Shigeru Satake ${ }^{1-3}$, Chika Nakamura ${ }^{1}$, Yoshiyuki Minamide ${ }^{1}$, Shinobu Kudo ${ }^{1}$, \\ Hiroshi Maeda $^{1}$, Yutaka Chihaya ${ }^{1}$, Yasuhiro Kamimura ${ }^{1}$, Hiroaki Miyajima ${ }^{1}$, \\ Jun Sasaki ${ }^{2}$, Masanobu Goryo ${ }^{2,3}$, and Kosuke Okada ${ }^{2,3}$ \\ ${ }^{1}$ Shin Nippon Biomedical Laboratories Co., Ltd., 2438 Miyanoura Kagoshima-shi, Kagoshima 891-1394, Japan \\ 2 Department of Veterinary Pathology, Faculty of Agriculture, Iwate University, 3-18-8 Ueda, Morioka-shi, Iwate 020- \\ 8550, Japan \\ ${ }^{3}$ The United Graduate School of Veterinary Sciences, Gifu University, 1-1 Yanagido, Gifu-shi, Gifu 501-1193, Japan
}

\begin{abstract}
To elucidate the effect of a large dose of di (2-ethylhexyl) phthalate (DEHP), a plasticizer and peroxisome proliferator-activated receptor- $\alpha(\operatorname{PPAR} \alpha)$ agonist, on hepatic peroxisomes, we orally administered 1,000 mg/kg/day, once daily, to 3 male and 4 female cynomolgus monkeys for 28 days consecutively. Light-microscopic and electron microscopic examinations of the liver were carried out in conjunction with measurement of the hepatic fatty acid $\beta$ oxidation system (FAOS), carnitine acetyltransferase (CAT) and carnitine palmitoyltransferase (CPT) activities, which are peroxisomal and/or mitochondrial enzyme activities. Electron microscopically, enlargement of the mitochondria was observed with lamellar orientation of the cristae along the major axis. Although the number of peroxisomes showed a tendency to increase when compared with those in a biopsied specimen before treatment, no abnormality in morphology was observed. A slight increase in CPT activity was noted at termination. No changes were noted in hepatic FAOS or CAT activity. In conclusion, although repeated oral treatment of cynomolgus monkeys with a large dose of DEHP induced a subtle increase in the numbers of peroxisomes with slight enlargements of the mitochondria, this lowsensitivity response to peroxisome proliferators in cynomolgus monkeys was considered to be closer to the response in humans than that in rodents. (J Toxicol Pathol 2010; 23: 75-83)
\end{abstract}

Key words: cynomolgus monkey, Di (2-ethylhexyl) phthalate (DEHP), hepatocyte, mitochondria, peroxisome

\section{Introduction}

Species differences in response to peroxisome proliferators including fibrates as hypolipidemic agents are well-known ${ }^{1-4}$. Generally, rodents such as mice and rats exhibit a high susceptibility to these peroxisome proliferators with consequent hepatomegaly and hepatocarcinogenesis ${ }^{1-4}$. However, nonhuman primates showed no such sensitivity ${ }^{5,6}$ according to the report of Reddy et $a .^{7}$; on the other hand, the fibrate derivative ciprofibrate evoked hepatic peroxisome proliferation in cynomolgus and rhesus monkeys, pigs, cats and chickens. Similarly, Hoivik et al. ${ }^{8}$ confirmed that treatment of cynomolgus monkeys with high doses of fenofibrate or

Received: 6 October 2009, Accepted: 1 December 2009 Mailing address: Shigeru Satake, Shin Nippon Biomedical Laboratories Co., Ltd., 2438 Miyanoura Kagoshima-shi, Kagoshima 891-1394, Japan

TEL: 81-19-623-7804 FAX: 81-19-623-7804

E-mail: satake-shigeru@snbl.co.jp ciprofibrate caused hepatic peroxisome proliferation in a dose-dependent manner. Therefore, it was considered that nonhuman primates would be likely to possess a proliferative reaction, although it would be a minor response.

Di (2-ethylhexyl) phthalate (DEHP), a plasticizer and its metabolites are peroxisome proliferator-activated receptor- $\alpha$ (PPAR $\alpha$ ) agonist, has previously been shown to induce peroxisomal proliferation in the livers of rats when administered at $100 \mathrm{mg} / \mathrm{kg} /$ day for 14 and 21 days $^{9,10}$. In contrast, it has been reported that DEHP did not provoke such alterations in the livers of marmosets and cynomolgus monkeys when administered at 2,500 mg/kg/day for 13 weeks $^{11}$ and at $500 \mathrm{mg} / \mathrm{kg} /$ day for 14 or 21 days $^{9,12}$, respectively. Accordingly, cynomolgus monkeys were not treated with a higher dose of DEHP in these studies. In our previous study ${ }^{13}$, repeated oral treatment of cynomolgus monkeys with a large dose ( 1,000 or $2,500 \mathrm{mg} / \mathrm{kg} /$ day) of DEHP showed a tendency to increase peroxisome proliferation in hepatocytes; however, a small number of animals was used without any corresponding control. Additionally, at $1,000 \mathrm{mg} / \mathrm{kg} /$ day of DEHP, body weight 
Table 1. Experimental Design

\begin{tabular}{lccccc}
\hline Test articles & $\begin{array}{c}\text { Dose level } \\
\text { (mg/kg/day) }\end{array}$ & $\begin{array}{c}\text { Volume } \\
(\mathrm{mL} / \mathrm{kg} / \text { day) }\end{array}$ & $\begin{array}{c}\text { Concentration } \\
\text { (mg/mL) }\end{array}$ & \multicolumn{2}{c}{ Number of animals (Animal No.) } \\
Males & Females \\
\hline Corn oil* & - & 5 & - & $3(1$ to 3) & $3(4$ to 6) \\
DEHP* & 1000 & 5 & 200 & 3 (7 to 9) & $4(10$ to13) \\
\hline
\end{tabular}

*: Orally administrated for 28 consecutive days.

deceased by around $10 \%$, and enlargement of the mitochondria with lamellar orientation of the cristae along the major axis was observed in two females. A dosage level of $2,500 \mathrm{mg} / \mathrm{kg} / \mathrm{day}$ was not considered to be feasible because the body weight decreased by approximately $40 \%$ and hepatic atrophy was observed in one female. These findings implied that an appropriate evaluation could not be carried out, and $1,000 \mathrm{mg} / \mathrm{kg} /$ day was thought to be the upper limit in cynomolgus monkeys. In the present investigation, therefore, to elucidate whether a high dose of DEHP evokes peroxisomal proliferation with mitochondrial alterations in cynomolgus monkeys, we orally administered a high dose (1,000 mg/kg/day) of DEHP to both sexes for 28 days consecutively.

\section{Materials and Methods}

The present study was approved by the Institutional Animal Care and Use Committee and was conducted in accordance with the bylaws of the committee.

\section{Chemicals}

Di (2-ethylhexyl) phthalate (DEHP, Lot No. 4YNPE) was purchased from Tokyo Chemical Industry Co., Ltd. (Tokyo, Japan). All other chemicals and reagents were of the highest grade available from commercial sources, unless otherwise stated.

\section{Animals and housing conditions}

Six male and seven female cynomolgus monkeys (Macaca fascicularis) that were 3- to 5-year-olds, purposebred and from China were used. They were housed individually in stainless steel cages $(680 \mathrm{~mm} \mathrm{D} \times 620 \mathrm{~mm} \mathrm{~W}$ $\times 770 \mathrm{~mm} \mathrm{H}$ ) with an artificial lighting cycle of $12 \mathrm{hr}$ (06:00 to $18: 00$ ), a temperature range of 23 to $29^{\circ} \mathrm{C}$, a humidity range of 35 to $75 \%$ and 15 ventilation cycles/hour. Approximately $108 \mathrm{~g}$ (12 g × 9 pieces) of pellet food (Teklad Global Certified 25\% Protein Primate Diet, Harlan Sprague Dawley Inc., Indianapolis, IN, USA) was provided to each animal once daily. The remaining food was removed before dosing on the following day. Drinking water was available ad libitum from an automatic supply system.

During a 4-week-acclimation period, drinking water (15 $\mathrm{mL} / \mathrm{kg}$ ) was administered by gavage to each animal daily from 3 days before the initiation of dosing in the same manner as test article administration to acclimate the animal to the dosing procedure. The day before the initiation of dosing was designated as day minus 1 (day -1), the week before the initiation of dosing was designated as week minus 1 (week 1 ) and the first day of dosing was designated as day 1.

\section{Liver biopsy}

Liver biopsy for electron microscopy was conducted for all animals in the first week of the acclimation period (day $29,-26$ or -25). A portion of liver tissue (approximately 0.5 g) was removed with an electric knife (MESU-150, Mizuho Ikakogyo Co. Ltd., Tokyo, Japan) under ketamine hydrochloride anesthesia (50 mg/mL, $0.2 \mathrm{~mL} / \mathrm{kg}$, Kamud Drugs Pvt. Ltd., Navi Mumbai, India).

\section{Experimental design}

DEHP was administered orally once daily to three males and four females for 28 days consecutively at a dose level of $1,000 \mathrm{mg} / \mathrm{kg} /$ day by a nasogastric catheter (Size: 10Fr, Nipro Corporation, Osaka, Japan). DEHP was dissolved in corn oil at concentrations of $200 \mathrm{mg} / \mathrm{mL}$. Three males and three females receiving corn oil ( $5 \mathrm{~mL} / \mathrm{kg} / \mathrm{day}$ ) in the same manner as the DEHP group served as the vehicle control (Table 1).

During the dosing period, clinical signs were observed three times daily. Body weight was measured twice a week. Food consumption was measured daily. For food consumption, weekly mean values were calculated as g/ animal/day.

\section{Clinical pathology}

Hematology and blood chemistry were conducted twice during the acclimation period and once on day 26 of dosing. In blood, the erythrocyte count, leukocyte count, hematocrit value, hemoglobin concentration, reticulocyte ratio and differential leukocyte count were determined using a hematology system (ADVIA120: Siemens Healthcare Diagnostics, Tarrytown, NY, USA). In serum, aspartate aminotransferase, alanine aminotransferase, alkaline phosphatase, lactate dehydrogenase, creatine phosphokinase, total bilirubin, total protein, albumin, globulin, albumin/globulin ratio, total cholesterol, triglycerides, glucose, blood urea nitrogen, creatinine, inorganic phosphorus, calcium, sodium, potassium and chloride were quantified using an automatic analyzer (JCABM8: JEOL Ltd., Tokyo, Japan).

\section{Toxicokinetics}

Approximately $0.5 \mathrm{~mL}$ of blood was collected from the 
femoral vein of each animal including those in the vehicle control group using a syringe containing sodium heparin prior to dosing and 1, 2, 4, 6 and 24 hr after dosing on day 26. The blood samples were immediately cooled on ice and centrifuged at $4^{\circ} \mathrm{C}$ at $1,710 \times \mathrm{g}$ for $15 \mathrm{~min}$ to obtain plasma. The plasma was stored frozen at $-10^{\circ} \mathrm{C}$ or below until it was analyzed.

Concentrations of DEHP and its first metabolite, mono (2-ethylhexyl) phthalate (MEHP), in plasma were determined by a high-performance liquid chromatography (HPLC) system with a UV detector (Alliance\#2795, Waters Corporation, Milford, MA, USA). The area under the plasma concentration-time curve until $24 \mathrm{hr}$ after the $26^{\text {th }}$ dosing $\left(\mathrm{AUC}_{0-24 \mathrm{~h}}\right)$ for MEHP was calculated by the linear trapezoidal rule.

\section{Necropsy}

All animals were euthanized by exsanguination under sodium pentobarbital anesthesia $(64.8 \mathrm{mg} / \mathrm{mL}, 0.4 \mathrm{~mL} / \mathrm{kg}$, Tokyo Chemical Industry Co., Ltd., Tokyo, Japan) 24 hr following the final dosing. At necropsy, external appearance, internal organs and tissues were examined macroscopically. The livers were removed and weighed using an electronic balance (HF-3000, A \& D Co., Ltd., San Jose, CA, USA). The relative liver weight was calculated from the body weight on the day of necropsy. Liver tissue was collected for measurement of the below-stated peroxisomal enzyme activities and light and electron microscopy.

\section{Measurement of hepatic peroxisomal and mitochondrial enzyme activities}

The right lobe of the liver was perfused with ice-cold physiological saline, frozen immediately with liquid nitrogen and stored in a freezer at $-70^{\circ} \mathrm{C}$ or below before being assayed.

All procedures described below were conducted under ice-cold conditions. After the collected liver tissue was cut into small portions with scissors, an amount of Tris buffer containing $1 \mathrm{mmol} / \mathrm{L}$ EDTA ( $\mathrm{pH} 7.4$ ) equal to nine times the liver tissue weight was added. The tissue was homogenized to prepare a $10 \%$ hepatic homogenate.

The activities of fatty acid $\beta$-oxidation system (FAOS), carnitine acetyltransferase (CAT) and carnitine palmitoyltransferase (CPT) in the $10 \%$ hepatic homogenates were measured by a spectrophotometer (U-3010, Hitachi, Ltd., Tokyo, Japan) using a previously reported method ${ }^{14}$. Each activity is reported as $\mu \mathrm{mol} / \mathrm{min} / \mathrm{g}$ liver.

\section{Light microscopy}

After excision at necropsy, the liver was fixed in $10 \%$ neutral buffered formalin and embedded in paraffin wax. Approximately 4- $\mu \mathrm{m}$ paraffin sections were stained with hematoxylin and eosin (HE) and examined microscopically.

\section{Electron microscopy}

The portions of liver tissue obtained by biopsy before treatment and after exsanguination at necropsy were fixed in $2.5 \%$ glutaraldehyde and $1 \%$ osmium tetroxide and embedded in epoxy resin (Quetol 812). Ultra-thin specimens ( 0.05 to $0.1 \mu \mathrm{m}$ ) were stained with uranyl acetate and lead citrate and examined by transmission electron microscopy (JEM-1200EX, JEOL, Ltd., Tokyo, Japan).

The numbers of peroxisomes and mitochondria in the hepatocytes in the centrilobular or periportal area in 40 images of liver tissue were counted at 6,500 $\times$ magnification for each animal. The total area of the 40 images was approximately 3,300 $\mu \mathrm{m}^{2}$.

\section{Statistical analysis}

Quantitative data were analyzed statistically to compare the vehicle control and DEHP groups. Additionally, the data from electron microscopy were analyzed to compare the values from before and after repeated treatment. They were first analyzed for homogeneity of variance by Bartlett's test. When the variance was homogeneous, a one-way analysis of variance was applied. When the result was significant, Dunnett's test was applied. When the variance was heterogeneous by Bartlett's test, the data were analyzed by the Kruskal-Wallis test. When the result was significant, a Dunnett-type test was applied. The MUSCOT statistical analysis software (Yukms Co., Ltd., Tokyo, Japan) was used for these statistical analyses at a significance level of 5\%.

\section{Results}

\section{Pathological findings in the liver}

In macroscopic and light microscopic examinations, no abnormality related to DEHP treatment was observed.

In regard to organ weights, no statistically significant differences were noted the liver; however, slight increases both in absolute and relative weights were noted in two females (Animal Nos. 10 and 13) that showed no body weight loss in the DEHP group (Table 2). The increase ratios were 22 or $24 \%$ for the relative weight when compared with the mean values in the corn oil group. The relative weight of 1 other female (Animal No. 11) in the DEHP group increased; however, the absolute weight did not increase, and body weight loss was observed in this animal.

Electron-microscopically, enlargement of the mitochondria with lamellar orientation of the cristae along the major axis was observed in one female (Animal No. 13) in the DEHP group (Fig. 1). Some mitochondria showed elongated enlargement.

In the DEHP-treated females, the numbers of peroxisomes in both centrilobular and periportal areas increased significantly $\left({ }^{* *} \mathrm{p}<0.01\right)$ at the end of the dosing period compared with those before treatment (Fig. 2). The individual increase ratios were $33.3 \%$ to $111.4 \%$ and $38.5 \%$ to $81.3 \%$ in the centrilobular and periportal areas, respectively; however, no significant changes were noted in mitochondria (Fig. 3). In the DEHP-treated males, no statistically significant differences in the numbers of peroxisomes or mitochondria were noted; however, the 
Table 2. Organ Weights of the Livers of Cynomolgus Monkeys Orally Administrated Corn Oil or DEHP at 1,000 mg/kg/ day for 28 Consecutive Days

Absolute Weight

\begin{tabular}{|c|c|c|c|c|c|}
\hline \multirow[b]{2}{*}{ Group } & \multicolumn{2}{|c|}{ Male } & \multicolumn{2}{|c|}{ Female } & \\
\hline & Animal No. & (g) & Animal No. & (g) & \\
\hline \multirow[t]{4}{*}{ Corn oil } & 1 & 70.6 & 4 & 59.4 & \\
\hline & 2 & 70.4 & 5 & 44.7 & \\
\hline & 3 & 79.4 & 6 & 61.5 & \\
\hline & Mean \pm SD & $73.47 \pm 5.14$ & Mean \pm SD & $55.20 \pm 9.15$ & \\
\hline \multirow[t]{5}{*}{ DEHP } & 7 & 81.1 & 10 & 66.2 & $\uparrow$ \\
\hline & 8 & 65.3 & 11 & 57.2 & \\
\hline & 9 & 68.0 & 12 & 48.9 & \\
\hline & - & - & 13 & 71.9 & $\uparrow$ \\
\hline & Mean \pm SD & $71.47 \pm 8.45$ & $\overline{\text { Mean } \pm \text { SD }}$ & $61.05 \pm 10.11$ & \\
\hline
\end{tabular}

Not significantly different from the corn oil group.

Relative Weight per Body Weight

\begin{tabular}{|c|c|c|c|c|c|}
\hline \multirow[b]{2}{*}{ Group } & \multicolumn{2}{|c|}{ Male } & \multicolumn{2}{|c|}{ Female } & \\
\hline & Animal No. & (g/kg) & Animal No. & (g/kg) & \\
\hline \multirow[t]{4}{*}{ Corn oil } & 1 & 16.2 & 4 & 22.0 & \\
\hline & 2 & 17.8 & 5 & 19.0 & \\
\hline & 3 & 20.7 & 6 & 18.9 & \\
\hline & Mean \pm SD & $18.23 \pm 2.30$ & Mean \pm SD & $19.98 \pm 1.75$ & \\
\hline \multirow[t]{5}{*}{ DEHP } & 7 & 19.7 & 10 & 24.4 & $\uparrow$ \\
\hline & 8 & 20.2 & 11 & 25.8 & $\uparrow$ \\
\hline & 9 & 21.1 & 12 & 20.0 & \\
\hline & - & - & 13 & 24.7 & $\uparrow$ \\
\hline & Mean \pm SD & $20.34 \pm 0.71$ & Mean \pm SD & $23.74 \pm 2.53$ & \\
\hline
\end{tabular}

Not significantly different from the corn oil group.

numbers of peroxisomes in the periportal area showed a tendency to increase; i.e., the mean value was higher than those before treatment or in the corn oil group (Fig. 2, 3).

\section{Hepatic peroxisomal and mitochondrial enzymes}

The activity of the mitochondrial enzyme CPT increased significantly in the males treated with DEHP, at 1.6 fold higher (2.043 units for corn oil versus 3.313 units for DEHP). No statistically significant differences were observed in the FAOS or CAT activities (Fig. 4).

\section{Toxicokinetics}

Extremely low concentrations (2.0-9.0 $\mu \mathrm{g} / \mathrm{mL})$ of the parent compound DEHP in plasma were detected sporadically at 1 to $6 \mathrm{hr}$ after dosing in two males and two females in the DEHP group. Meanwhile, its first metabolite, MEHP, increased with time after dosing in all animals in the DEHP group. The plasma MEHP concentration reached a maximum at 4 to $6 \mathrm{hr}$ after dosing. The individual Cmax values ranged from 39.2 to $70.5 \mu \mathrm{g} / \mathrm{mL}$, and the mean Cmax value in the DEHP group was $51.3 \pm 10.8 \mu \mathrm{g} / \mathrm{mL}$. The individual AUC0-24h values ranged from 517.6 to 1374.2 $\mu \mathrm{g} \cdot \mathrm{hr} / \mathrm{mL}$, and the mean $\mathrm{AUC}_{0-24 \mathrm{~h}}$ in the DEHP group was
$826.6 \pm 271.2 \mu \mathrm{g} \cdot \mathrm{hr} / \mathrm{mL}$.

\section{Clinical observations and laboratory tests}

In regard to clinical signs, as abnormalities related to DEHP treatment, soft stool and/or diarrhea were observed in all males and females almost every day. Vomiting was observed in one male and one female on day 3 or 26.

In regard to body weight, a decrease was observed in two males and one female (Animal Nos. 8, 9 and 11) in the DEHP group at the end of the dosing period when compared with the first day of dosing (Fig. 5). The decrease ratios in these animals were $10.0 \%, 15.5 \%$ and $24.2 \%$. No abnormalities were observed in any other animal.

In regard to food consumption, the mean values of food consumption throughout the dosing period were decreased in one male and one female (Animal Nos. 9 and 11) in the DEHP group. The decrease ratios of the mean values in these animals were $43 \%$ and $44 \%$, respectively, when compared with the mean values in weeks -2 to -1 . No abnormalities were observed in any other animal.

In regard to blood chemistry, serum lipids (total cholesterol or triglyceride) did not decrease in the DEHP group (Table 3 ). An increase in triglycerides was noted in 1 

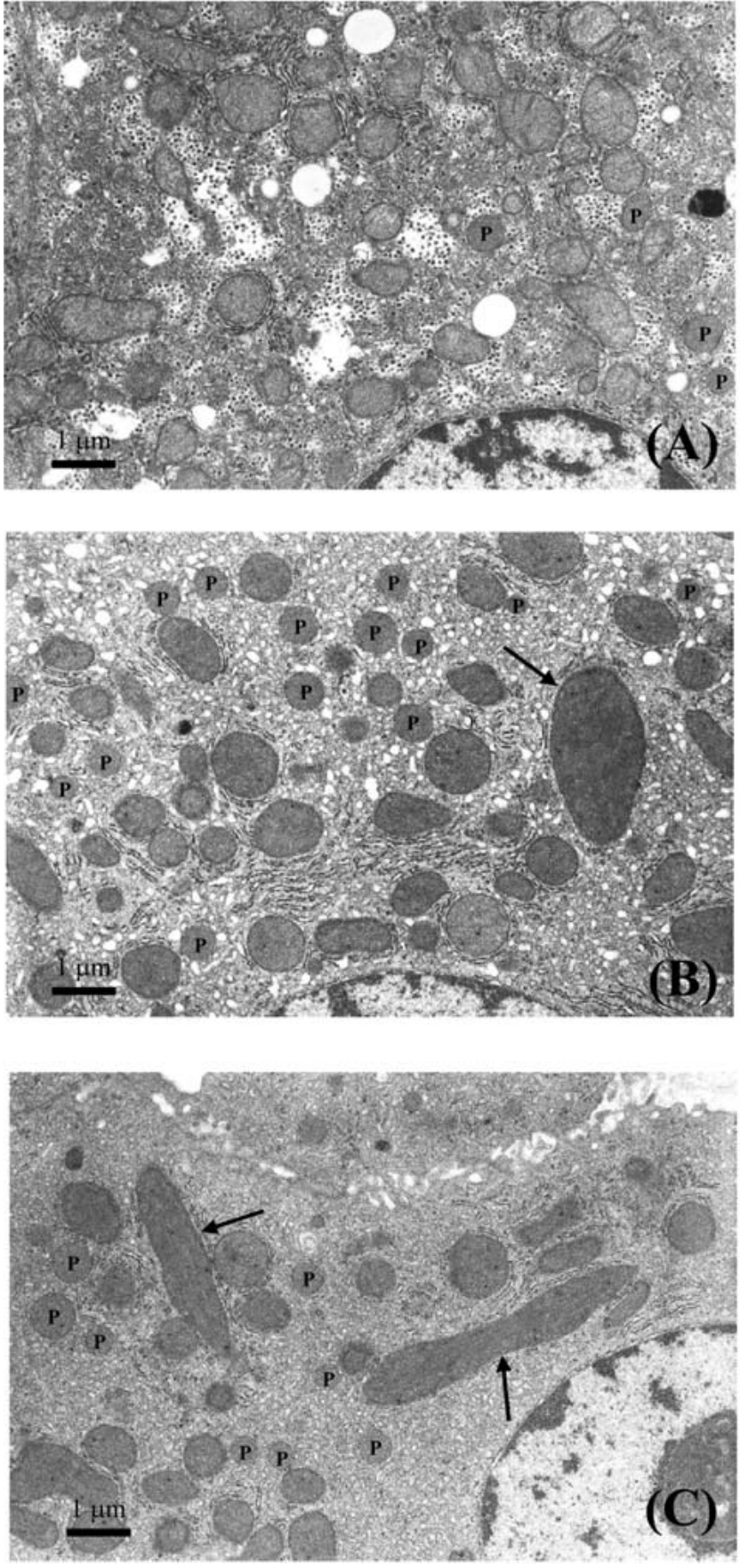

Fig. 1. Electron microphotographs of periportal hepatocytes in a female cynomolgus monkey orally administrated DEHP at $1,000 \mathrm{mg} / \mathrm{kg} /$ day for 28 consecutive days. (A) Before treatment: No abnormal changes were observed. (B) Same animal after treatment: Peroxisomes increased in the hepatocyte. Lamellar orientation of cristae along the major axis was observed in the enlarged mitochondria (arrows). (C) Same animal after treatment: The mitochondria showed elongated enlargement. Lamellar orientation of cristae along the major axis was observed in the enlarged mitochondria (arrows). P: Peroxisome.

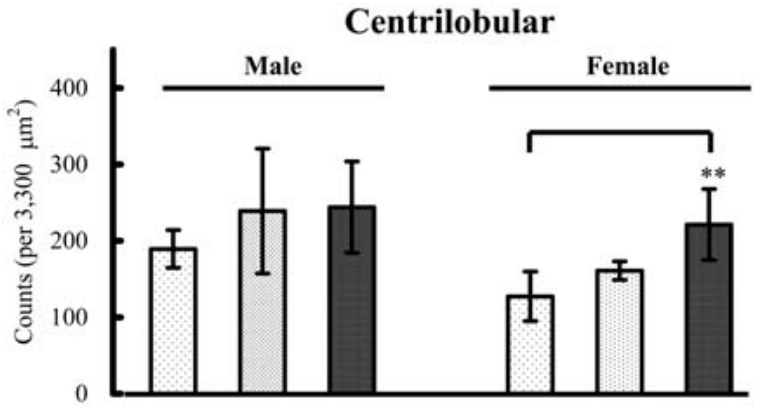

(A)

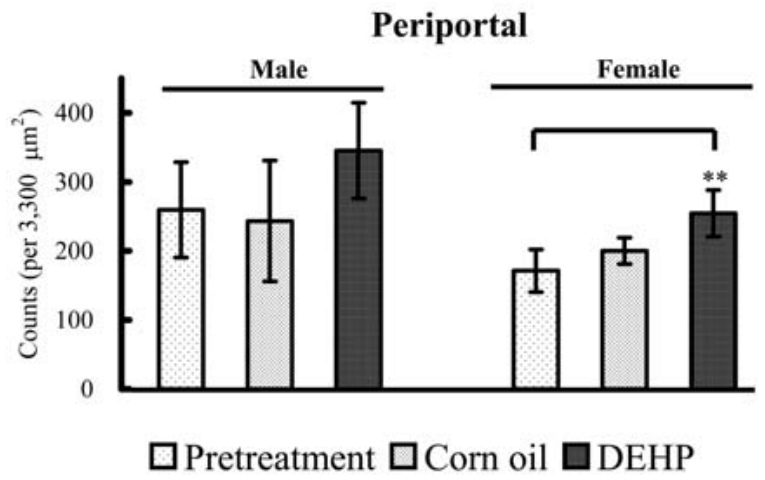

(B)

Fig. 2. Number of hepatic peroxisomes in cynomolgus monkeys orally administrated DEHP at $1,000 \mathrm{mg} / \mathrm{kg} /$ day for 28 consecutive days. Monkeys given corn oil in the same manner served as the vehicle control. Columns and vertical bars show the mean values and SD of 3-7 animals, respectively. $* * \mathrm{P}<0.01$ : significantly different from the values at pretreatment.

female (Animal No. 11) in the DEHP group. In regard to hematology, no abnormality related to DEHP treatment was observed.

\section{Discussion}

Statistically significantly increased numbers of peroxisomes in the centrilobular and periportal areas were observed in the DEHP-treated females compared with before treatment. In the DEHP-treated males, no statistically significant differences were noted; however, the numbers of peroxisomes in the periportal area were higher than those before treatment or in the corn oil group. These results suggested that a large dose of DEHP induced an increase in the numbers of peroxisomes. On the other hand, no significant differences were observed when compared with the corn oil group in the numbers of peroxisomes in the males or females. No differences were observed in the peroxisomal enzyme activities in liver homogenates between the DEHP and corn oil groups. These results suggested that the peroxisome proliferation was subtle. In our previous study ${ }^{13}$, we could not reach a conclusion as to whether or not DEHP induced peroxisome proliferation. We added the 


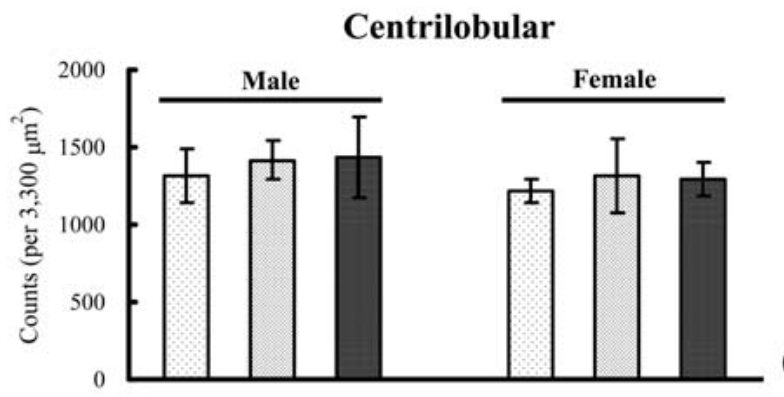

(A)

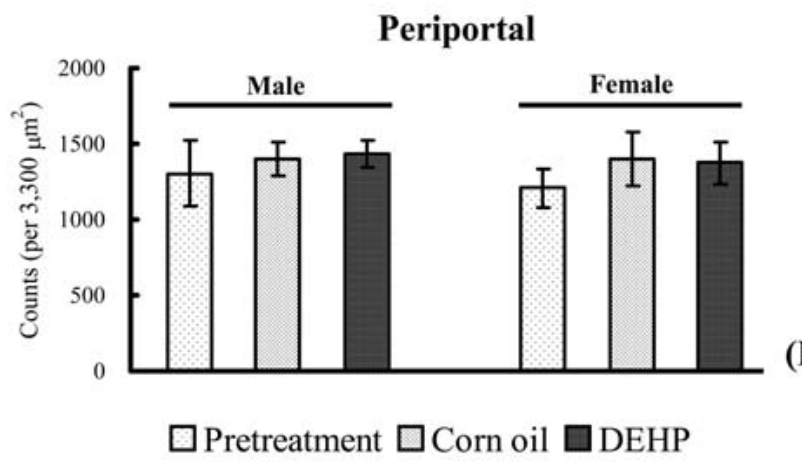

Fig. 3. Number of hepatic mitochondria in cynomolgus monkeys orally administrated DEHP at $1,000 \mathrm{mg} / \mathrm{kg} /$ day for 28 consecutive days. Monkeys given corn oil in the same manner served as the vehicle control. Columns and vertical bars show the mean values and SD of 3-7 animals, respectively.

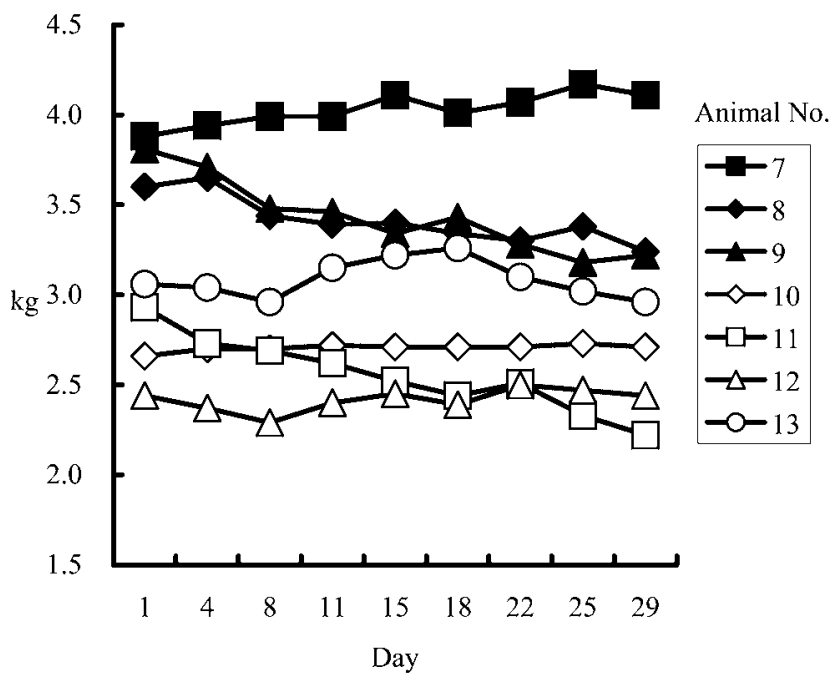

Fig. 5. Body weights of cynomolgus monkeys orally administrated DEHP at $1,000 \mathrm{mg} / \mathrm{kg} /$ day for 28 consecutive days.

biopsy before treatment and a vehicle control and increased the number of animals in the present study. As a consequence, we were able to conclude that DEHP induced a subtle change in hepatic peroxisome proliferation in the cynomolgus monkeys.

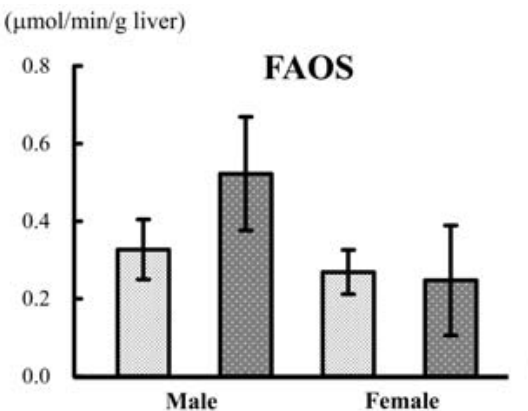

(A)

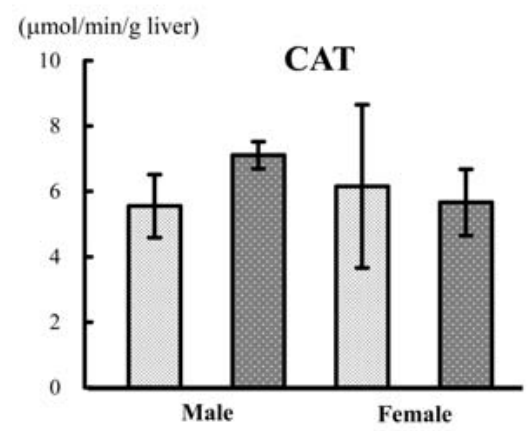

(B)

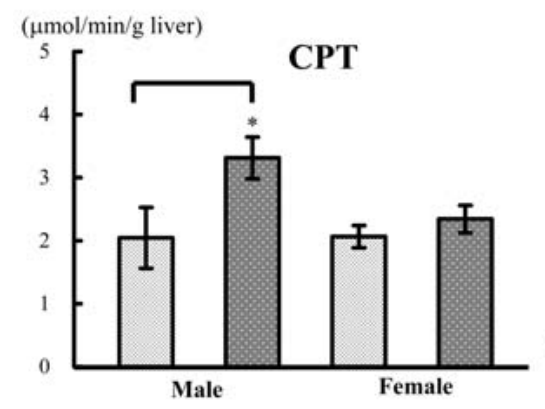

(C)

Fig. 4. Fatty acid $\beta$-oxidation system (FAOS), carnitine acetyltransferase (CAT) and carnitine palmitoyltransferase (CPT) activities in the liver homogenates of cynomolgus monkeys orally administrated DEHP at $1,000 \mathrm{mg} / \mathrm{kg} /$ day for 28 consecutive days. Monkeys given corn oil in the same manner served as the vehicle control. Columns and vertical bars show the mean values and SD of 3 or 4 animals, respectively. ${ }^{*} \mathrm{P}<0.05$ : significantly different from the corn oil group.

In our previous study ${ }^{13}$, morphological changes of mitochondria, such as enlargement and lamellar orientation of the cristae along the major axis, were observed in 2 female cynomolgus monkeys whose body weights decreased at ratios of $10.7 \%$ or $11.7 \%$ at $1,000 \mathrm{mg} / \mathrm{kg} /$ day of DEHP, and the possibility that malnutrition could have caused the mitochondrial changes was suggested. In the present study, mitochondrial abnormalities were observed in one female; however, body weight loss was not noted in this animal. Mitochondrial changes caused by peroxisome proliferators have previously been reported as follows: DEHP induced increases in both the size and number of mitochondria in hepatocytes in rats ${ }^{15,16}$, and other PPAR $\alpha$ agonists (ciprofibrate and fenofibrate) induced an increase in number 
Table 3. Serum Lipids in Cynomolgus Monkeys Orally Administrated Corn Oil or DEHP at 1,000 mg/kg/day for 28 Consecutive Days

\begin{tabular}{|c|c|c|c|c|c|c|}
\hline \multirow[b]{2}{*}{ Group } & \multirow[b]{2}{*}{ Animal No./Day } & \multicolumn{2}{|c|}{$\begin{array}{c}\text { Total cholesterol } \\
(\mathrm{mg} / \mathrm{dL})\end{array}$} & \multicolumn{2}{|c|}{$\begin{array}{c}\text { Triglyceride } \\
(\mathrm{mg} / \mathrm{dL})\end{array}$} & \\
\hline & & Day -5* & Day $26 *$ & Day $-5^{*}$ & Day 26* & \\
\hline \multicolumn{7}{|l|}{ Control (Male) } \\
\hline \multirow[t]{5}{*}{ Corn oil } & 1 & 122 & 111 & 59 & 33 & \\
\hline & 2 & 76 & 79 & 35 & 39 & \\
\hline & 3 & 137 & 137 & 48 & 40 & \\
\hline & Mean & 111.7 & 109.0 & 47.3 & 37.3 & \\
\hline & SD & 31.8 & 29.1 & 12.0 & 3.8 & \\
\hline \multicolumn{7}{|l|}{ DEHP (Male) } \\
\hline \multirow[t]{5}{*}{$1,000 \mathrm{mg} / \mathrm{kg} / \mathrm{day}$} & 7 & 93 & 84 & 26 & 22 & \\
\hline & 8 & 92 & 93 & 43 & 37 & \\
\hline & 9 & 74 & 103 & 14 & 34 & \\
\hline & Mean & 86.3 & 93.3 & 27.7 & 31.0 & \\
\hline & SD & 10.7 & 9.5 & 14.6 & 7.9 & \\
\hline \multicolumn{7}{|l|}{ Control (Female) } \\
\hline \multirow[t]{5}{*}{ Corn oil } & 4 & 153 & 157 & 34 & 18 & \\
\hline & 5 & 129 & 117 & 44 & 49 & \\
\hline & 6 & 126 & 126 & 29 & 49 & \\
\hline & Mean & 136.0 & 133.3 & 35.7 & 38.7 & \\
\hline & SD & 14.8 & 21.0 & 7.6 & 17.9 & \\
\hline \multicolumn{7}{|l|}{ DEHP (Female) } \\
\hline \multirow[t]{6}{*}{$1,000 \mathrm{mg} / \mathrm{kg} /$ day } & 10 & 156 & 136 & 33 & 35 & \\
\hline & 11 & 175 & 195 & 52 & 285 & $\uparrow$ \\
\hline & 12 & 136 & 123 & 27 & 41 & \\
\hline & 13 & 139 & 137 & 24 & 25 & \\
\hline & Mean & 151.5 & 147.8 & 34.0 & 96.5 & \\
\hline & SD & 18.0 & 32.1 & 12.6 & 125.8 & \\
\hline
\end{tabular}

Not significantly different from the corn oil group.

*: The day before initiation of dosing was designated as day -1 , and the first day of dosing was designated as day 1 .

and elongation of mitochondria in hepatocytes in cynomolgus monkeys ${ }^{8}$. Additionally, peroxisome and mitochondria are closely associated with each other in PPAR $\alpha$ agonist-related metabolism. Consequently, there is a high possibility that the mitochondrial changes observed in the present study were caused by effects of DEHP on the hepatocytes. The toxicological significance and mechanism of the mitochondrial changes were unclear in the present study, and other approaches from the standpoint of molecular biology would seem to be required.

CPT is widely known to be a fatty acid oxidation ratelimiting enzyme in the mitochondria. Hepatic CPT activity increased in males treated with DEHP but not in females, and morphological changes of the mitochondria were observed only in females. Thus, the relation between the morphological changes of the mitochondria and increased activity of CPT was unclear. It has been reported that PPAR $\alpha$ agonists such as fibrates increase hepatic CPT, FAOS and CAT activities two- to five-fold or more and decrease serum lipids in rats ${ }^{17}$. In the present study, CPT activity increased 1.6-fold in the males; however, serum lipids did not decrease. An increase in triglycerides was noted in 1 female in the DEHP group; however, this was considered to be related innutrition because decreases in food consumption and body weight were noted in this animal.

In the present study and our previous study ${ }^{13}$, peroxisomal proliferation and mitochondrial changes were clearer in females than in males. The changes in both the females and males were slight. Consequently, the differences between females and males were slight; however, there seem to be sex-related differences in the response to peroxisome proliferators in cynomolgus monkeys. Sex differences in response to peroxisome proliferators such as crofibrate have been reported in rats ${ }^{18,19}$. Male rats are more sensitive than females, and it has been suggested that this is due to the influence of testosterone ${ }^{18}$. The result in the present study differed from the previously reported results in rats. It is possible that factors other than testosterone had an influence in the cynomolgus monkeys, but this was uncertain.

A number of experiments have suggested that there are species differences in the expression of PPAR $\alpha$ and response to PPAR $\alpha$ agonists (including differences in receptor activation, peroxisome proliferation and induction of target genes), which are higher in rodents than in other species $^{20-26}$. Additionally, there is a wide range of receptor 
affinities for different PPAR $\alpha$ ligands ${ }^{26}$. The lower reactivity of cynomolgus monkeys to DEHP may be explained by these differences.

MEHP is the first metabolite of DEHP and is a PPAR $\alpha$ agonist. The first stage in metabolism of DEHP is hydrolysis to MEHP and 2-ethylhexanol. Hydrolysis to MEHP rapidly takes place in the intestine, and further hydrolysis takes place after absorption ${ }^{27,28}$. Additionally, hydrolysis to MEHP by plasma lipase takes place in blood samples ${ }^{29}$. The DEHP and MEHP concentrations in plasma might not have shown pharmacokinetically true values because there is a possibility that hydrolysis to MEHP took place during the procedure for obtaining plasma and/or its preservation. However, the increased plasma MEHP level revealed sufficient intestinal absorption of DEHP in the present study.

In the present study, we concluded that DEHP induced hepatic peroxisome proliferation in cynomolgus monkeys; however, the degree of increase was very low, hepatomegaly or hepatic proliferation was not observed and the exposure level was extremely high $(1,000 \mathrm{mg} / \mathrm{kg} /$ day $)$. In contrast, peroxisome proliferation was observed from $100 \mathrm{mg} / \mathrm{kg} /$ day in rats ${ }^{9,10}$. At the same time, our results reconfirmed that cynomolgus monkeys are sensitive to peroxisome proliferators. Reddy et $a .^{7}$ and Hoivik et al. ${ }^{8}$ reported that treatment with high doses of fenofibrate or ciprofibrate caused hepatic peroxisome proliferation in cynomolgus monkeys. In humans, previous investigations have reported that human hepatocytes are insensitive to peroxisome proliferators $^{30,31}$. On the other hand, Ganning et al. ${ }^{32,33}$ reported that liver biopsies taken from dialysis patients showed hepatic peroxisome proliferation and concluded that this was caused by phthalate esters having migrated from tubes or bags that were made of polyvinyl chloride plastics. In their reports, although quantitative data for the peroxisome count was not reported, peroxisome proliferation in humans was considered to be subtle based on electron micrographs ${ }^{32,33}$. We can assume that hepatic peroxisome proliferation in human resulting from DEHP is subtle, just as in the case of cynomolgus monkeys. There have been no reports showing that peroxisome proliferators induce mitochondrial changes in humans. The issue for peroxisome proliferators is the risk of hepatocarcinogenesis, not peroxisome proliferation itself. Hoivik et al. ${ }^{8}$ suggested that the primate may be refractory to PPAR-induced hepatocarcinogenesis because cynomolgus monkeys responded to fibrates in a manner that is different from the rodent; that is to say, there was no indication of cell proliferation, and there was no remarkable increase in the mRNA levels for most proteins known to respond to oxidative stress. In fact, there have been no reports showing that peroxisome proliferators cause hepatocarcinogenesis in nonhuman primates or humans. Cynomolgus monkeys are now widely used as models in risk assessment of new chemicals and drugs. The response to peroxisome proliferators in cynomolgus monkeys was considered to be closer to that in humans than the response in rodents. However, further investigation into the causes of species differences appears to be necessary for accurate assessments of the risk of peroxisome proliferators for humans from the results in cynomolgus monkeys.

\section{References}

1. Platt DS and Thorp JM. Changes in the weight and composition of the liver in the rat, dog and monkey treated with ethyl chlorophenoxyisobutyrate. Biochem Pharmacol. 15: 915-925. 1966.

2. Lake BG and Gray TJ. Species differences in hepatic peroxisome proliferation. Biochem Soc Trans. 13: 859-861. 1985.

3. Rodricks JV and Turnbull D. Interspecies differences in peroxisomes and peroxisome proliferation. Toxicol Ind Health. 3: 197-212. 1987.

4. Fahimi HD, Baumgart E, Beier K, Pill J, Hartig F, and Volkl A. Ultrastructural and biochemical aspects of peroxisome proliferation and biogenesis in different mammalian species. In: Peroxisomes: Biology and importance in toxicology and medicine. G Gibson and B Lake (eds). London, Washington: Taylor and Francis. 395-424. 1993.

5. Blane GF and Pinaroli F. Fenofibrate: Animal toxicology in relation to side-effects in man (author's transl). Nouv Presse Med. 22: 3737-3746. 1980.

6. Graham MJ, Wilson SA, Winham MA, Spencer AJ, Rees JA, Old SL, and Bonner FW. Lack of peroxisome proliferation in marmoset liver following treatment with ciprofibrate for 3 years. Fundam Appl Toxicol. 22: 58-64. 1994.

7. Reddy JK, Lalwani ND, Qureshi SA, Reddy MK, and Moehle CM. Induction of hepatic peroxisome proliferation in non-rodent species, including primates. Am J Pathol. 114: 171-183. 1984.

8. Hoivik DJ, Qualls CW Jr, Mirabile RC, Cariello NF, Kimbrough CL, Colton HM, Anderson SP, Santostefano MJ, Morgan RJ, Dahl RR, Brown AR, Zhao Z, Mudd PN Jr, Oliver WB Jr, Brown HR, and Miller RT. Fibrates induce hepatic peroxisome and mitochondrial proliferation without overt evidence of cellular proliferation and oxidative stress in cynomolgus monkeys. Carcinogenesis. 25: 1757-1769. 2004.

9. Short RD, Robinson EC, Lington AW, and Chin AE. Metabolic and peroxisome proliferation studies with di(2ethylhexyl)phthalate in rats and monkeys. Toxicol Ind Health. 3: 185-195. 1987.

10. Lake BG, Gray TJ, Foster JR, Stubberfield CR, and Gangolli SD. Comparative studies on di-(2-ethylhexyl) phthalateinduced hepatic peroxisome proliferation in the rat and hamster. Toxicol Appl Pharmacol. 72: 46-60. 1984.

11. Kurata Y, Kidachi F, Yokoyama M, Toyota N, Tsuchitani M, and Katoh M. Subchronic toxicity of di(2ethylhexyl)phthalate in common marmosets: Lack of hepatic peroxisome proliferation, testicular atrophy, or pancreatic acinar cell hyperplasia. Toxicol Sci. 42: 49-56. 1988.

12. Pugh G Jr, Isenberg JS, Kamendulis LM, Ackley DC, Clare LJ, Brown R, Lington AW, Smith JH, and Klaunig JE. Effects of di-isononyl phthalate, di-2-ethylhexyl phthalate, and clofibrate in cynomolgus monkeys. Toxicol Sci. 56: 181-188. 2000.

13. Satake S, Tanigawa Y, Maeda H, Kamimura Y, Chihaya Y, 
Miyajima H, Goryo M, and Okada K. Morphological changes of mitochondria in the hepatocytes induced by administration of a large amount of di (2-ethylhexyl) phthalate (DEHP) to cynomolgus monkeys (Macaca fascicularis). J Toxicol Pathol. 21: 73-75. 2008.

14. Inoue K and Nakagawa S. Lipid III neutral lipid, lipoprotein and serum lipid, lipid peroxide. In: Seibutsu Yakkagaku Jikken Koza 3, Ichikawa A (ed). Hirokawa Publishing Co. Tokyo, 100-112. 2002 (In Japanese).

15. Mitchell FE, Prince SC, Hinton RH, Grasso P, and Bridges JW. Time and dose-response study of the effects on rats of the plasticizer di(2-ethylhexyl) phthalate. Toxicol Appl Pharmacol. 81: 371-392. 1985.

16. Nair $\mathrm{N}$ and Kurup $\mathrm{CK}$. Effect of administration of diethylhexyl phthalate on the function and turnover of rat hepatic mitochondria. Biochim Biophys Acta. 925: 332-340. 1987.

17. Watanabe T. Drugs and hepatic peroxisome proliferation. Drug Metab Pharmacokinet. 1: 179-189. 1986.

18. Svoboda DJ. Unusual responses of rat hepatic and renal peroxisomes to RMI 14, 514, a new hypolipidemic agent. J Cell Biol. 78: 810-822. 1978.

19. Yamoto T, Ohashi Y, Furukawa T, Teranishi M, Manabe S, and Makita T. Change of the sex-dependent response to clofibrate in F344 rat liver during postnatal development. Toxicol Lett. 85: 77-83. 1996.

20. Doull J, Cattley R, Elcombe C, Lake BG, Swenberg J, Wilkinson C, Williams G, and Gemert MV. A cancer risk assessment of di(2-ethylhexyl)phthalate: Application of the new U.S. EPA risk assessment guidelines. Regul Toxicol Pharmacol. 29: 327-357. 1999.

21. Roberts RA. Peroxisome proliferators: mechanisms of adverse effects in rodents and molecular basis for species differences. Arch Toxicol. 73: 413-418. 1999.

22. Holden PR and Tugwood JD. Peroxisome proliferatoractivated receptor alpha: role in rodent liver cancer and species differences. J Mol Endocrinol. 22: 1-8. 1999.

23. Roberts RA, James NH, Hasmall SC, Holden PR, Lambe K, Macdonald N, West D, Woodyatt NJ, and Whitcome D. Apoptosis and proliferation in non-genotoxic carcinogenesis: species differences and role of PPARalpha. Toxicol Lett. 89: 112-113: 49-57. 2000.

24. Cariello NF, Romach EH, Colton HM, Ni H, Yoon L, Falls
JG, Casey W, Creech D, Anderson SP, Benavides GR, Hoivik DJ, Brown R, and Miller RT. Gene expression profiling of the PPAR-alpha agonist ciprofibrate in the cynomolgus monkey liver. Toxicol Sci. 88: 250-264. 2005.

25. Ito Y, Yamanoshita O, Kurata Y, Kamijima M, Aoyama T, and Nakajima T. Induction of peroxisome proliferatoractivated receptor alpha (PPARalpha)-related enzymes by di(2-ethylhexyl) phthalate (DEHP) treatment in mice and rats, but not marmosets. Arch Toxicol. 81: 219-226. 2007.

26. Jeffrey M, Connie C, and Frank JG. Peroxisome proliferatoractivated receptor- $\alpha$ and liver cancer: where do we stand? J Mol Med. 83: 774-785. 2005.

27. Williams DF, de Jong W, Thomsen M, Farre ER, Gatti AM, Paunio MK, Petersen AH, and Marquardt H. Opinion on medical devices containing DEHP plasticised PVC; Neonates and other groups possibly at risk from DEHP toxicity. http://www.hosmat.eu/toxicovigilance/ PvcDehp.pdf. 2002.

28. Rusyn I, Peters JM, and Cunningham ML. Modes of action and species-specific effects of di-(2-ethylhexyl)phthalate in the liver. Crit Rev Toxicol. 36: 459-479. 2006.

29. Peck CC, Odom DG, Friedman HI, Albro PW, Hass JR, Brady JT, and Jess DA. Di-2-ethylhexyl phthalate (DEHP) and mono-2-ethylhexyl phthalate (MEHP) accumulation in whole blood and red cell concentrates. Transfusion. 19: 137146. 2003.

30. Woodyatt NJ, Lambe KG, Myers KA, Tugwood JD, and Roberts RA. The peroxisome proliferator (PP) response element upstream of the human acyl CoA oxidase gene is inactive among a sample human population: Significance for species differences in response to PPs. Carcinogenesis. 20: 369-372. 1999.

31. Lawrence JW, Li Y, Chen S, DeLuca JG, Berger JP, Umbenhauer DR, Moller DE, and Zhou G. Differential gene regulation in human versus rodent hepatocytes by peroxisome proliferator-activated receptor (PPAR) $\alpha$. J Biol Chem. 276: 31521-31527. 2001.

32. Ganning AE, Brunk U, and Dallner G. Phthalate esters and their effect on the liver. Hepatology. 4: 541-547. 1984.

33. Ganning AE, Brunk U, Edlund C, Elhammer A, and Dallner G. Effects of prolonged administration of phthalate ester on the liver. Environ Health Perspect. 73: 251-258. 1987. 